
Not for reproduction, distribution or commercial use.

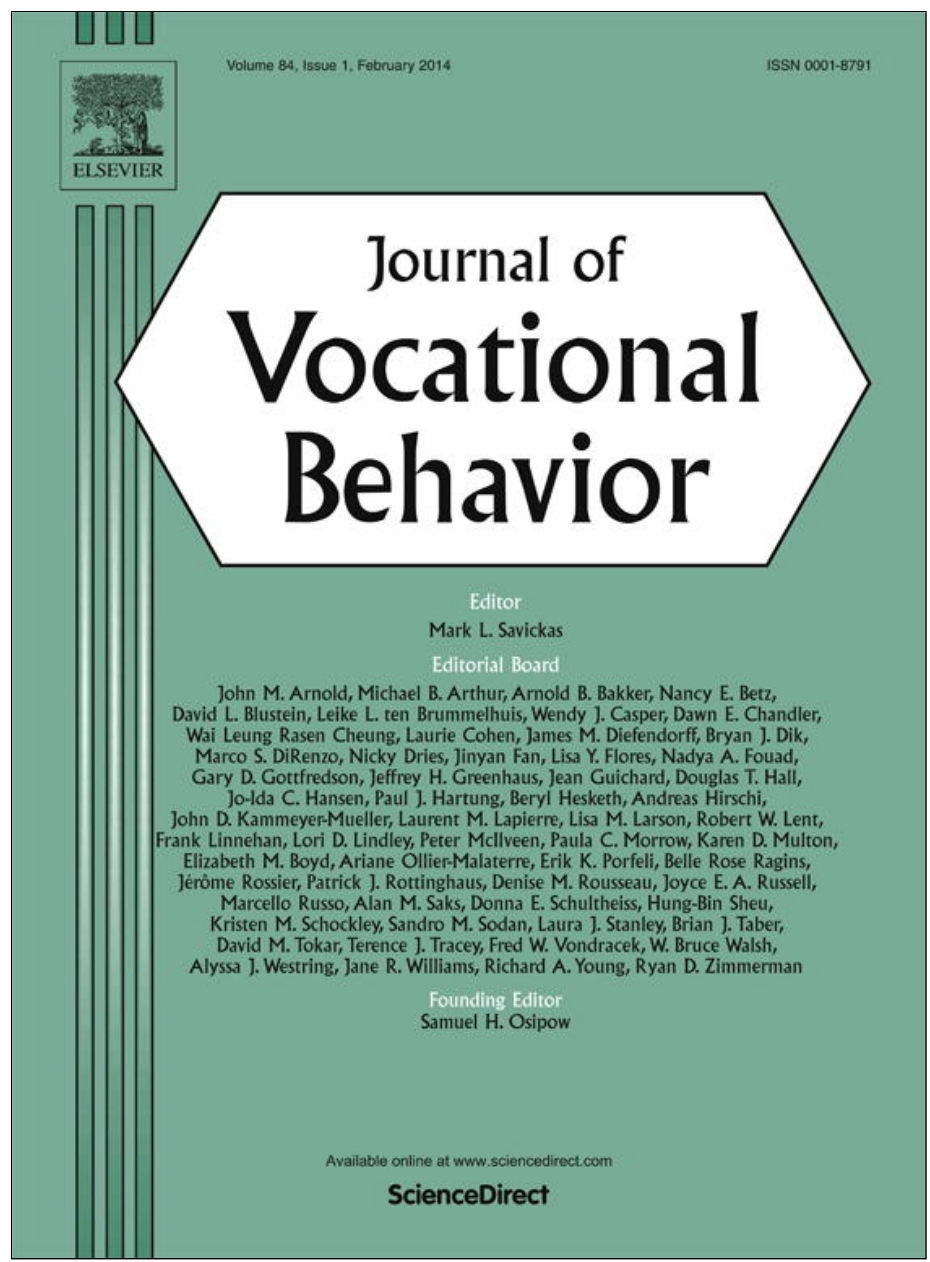

This article appeared in a journal published by Elsevier. The attached copy is furnished to the author for internal non-commercial research and education use, including for instruction at the authors institution and sharing with colleagues.

Other uses, including reproduction and distribution, or selling or licensing copies, or posting to personal, institutional or third party websites are prohibited.

In most cases authors are permitted to post their version of the article (e.g. in Word or Tex form) to their personal website or institutional repository. Authors requiring further information regarding Elsevier's archiving and manuscript policies are encouraged to visit: 


\title{
Innovative moments and change in Career Construction Counseling
}

\author{
Paulo Cardoso ${ }^{\mathrm{a}, *}$, Joana R. Silva ${ }^{\mathrm{b}}$, Miguel M. Gonçalves ${ }^{\mathrm{b}}$, Maria Eduarda Duarte ${ }^{\mathrm{c}}$ \\ a Department of Psychology, University of Évora, Portugal

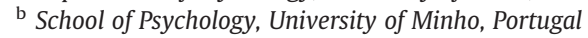 \\ c Faculty of Psychology, University of Lisbon, Portugal
}

\section{A R T I C L E I N F O}

\section{Article history:}

Received 2 August 2013

Available online 29 October 2013

\section{Keywords:}

Career Construction

Career Counseling Process

Change

Innovative Moments

\begin{abstract}
A B S T R A C T
This article presents an exploratory study of the process of change during Career Construction Counseling (CCC). The Innovative Moments Coding System (IMCS) and the Return to the Problem Coding System (RPCS) were used to an intensive analysis of a career counseling case - the case of Michael. Both systems are grounded in a narrative conception of the self which suggests that narrative change results from the elaboration and development of narrative exceptions to a client's core problematic self-narrative. The IMCS identifies and tracks the occurrence of five different types of narrative change and the RPCS tracks the ambivalence present in the clients discourse throughout the therapeutic process. This is the first attempt to use these methods with a career counseling case. The results suggest that the narrative elaboration progresses from the first to the third session. We discuss these results, emphasizing the process of change in career counseling with clients in which maladaptive repetition underlies career decision-making difficulties.
\end{abstract}

() 2013 Elsevier Inc. All rights reserved.

Career Construction Counseling (CCC) is a narrative practice of counseling that is grounded in the framework of Career Construction Theory (CCT; Savickas, 2005, 2013), which emphasizes the inter-subjective dimension of career counseling and is designed to help individuals re-author their narrative identity and to project into career roles new possibilities of selfconstruction (Savickas, 2011). In this framework, career construction is a continuous process throughout life span and across multiple life roles, which takes place while expressing self-organization dynamics. In fact, career plans are one of the mechanisms by which individuals give order and intentionality to their existence (Cardoso, 2012). Furthermore, through the choices that are made in different career roles, individuals seek to implement their self-concepts (Savickas, 2013).

This model of counseling is usually organized into three sessions. In the first session, a semi-structured interview is used - the Career Construction Interview (CCI) - to evoke opinions and experiences that are relevant to career choices (Savickas, 2011). Five topics are explored: (1) Role models (for self-construction); (2) books and movies for current script; (3) magazines or TV shows for manifest interests; (4) sayings or mottos for advice to one's self; and (5) early recollections for a current perspective on the presenting problem. In the second and third sessions, the counselor supports the client's self-exploration based on his/her answers to the five topics. The aim is to help the individual in elaborating the central problem of his/her life, assessing needs and promoting its resolution by formulating goals. The career counselor takes on the role of a meaningful co-constructor, attempting not to act as an expert on the client's experience and acting instead as a facilitator who prompts the client to examine and deepen the meaning of that experience.

\footnotetext{
* Corresponding author at: Departamento de Psicologia, Universidade de Évora, Apartado 94, 7002-554 Lisboa, Portugal.

E-mail address: pmsc@uevora.pt (P. Cardoso).
} 
There are only a few research studies on CCC, including some outcome studies on individual (Refhuss, Del Corso, Glavin, \& Wykes, 2011) and group counseling (Di Fabio \& Maree, 2011), as well as a study that is focused on the counselor's perspective on the intervention (Refhuss, Cosio, \& Del Corso, 2011). These studies support CCC efficacy in career counseling. However, as far as we know, no empirical study of the process of CCC change has yet been published. Thus, this research presents an exploratory study in which the process of change during CCC is addressed and thereby it is a response to the call for studies of the underlying processes and mechanisms that lead to effective change during career counseling (Heppner \& Heppner, 2002; Whiston \& Rahardja, 2008). The main question is how the client reconstructs meaning during the 3 sessions of the counseling process. To address that question, we used a methodological tool that was recently developed in psychotherapy research, which aims at studying the development of novelties along the treatment - the Innovative Moments Model (Gonçalves, Matos, \& Santos, 2009; Gonçalves, Ribeiro, Mendes, Matos, \& Santos, 2011).

\subsection{Innovative Moments Coding System (IMCS): tracking novelties in psychotherapy}

Similar to CCC, the innovative moments model is grounded on the narrative concept of the self, which suggests that people construct and organize their personal meaning in the form of self-narratives, which they narrate to themselves and to others (Hermans \& Hermans-Jansen, 1995; McAdams, 1993; Sarbin, 1986; White \& Epston, 1990). Based on this assumption, psychological suffering is conceptualized as the result of problematic meaning construction (Dimaggio, 2006; Gonçalves et al., 2009; White \& Epston, 1990). Problematic self-narratives are often too rigid and are dominated by difficult themes (e.g., self-devaluation), which constrain the individual's meaning construction and, as a result, limits his or her life options (Cardoso, 2012; Dimaggio, 2006; Gonçalves et al., 2009; Hermans \& Hermans-Jansen, 1995). According to the innovative moments model, change is achieved by the emergence of narrative details outside of the dominant and problematic self-narrative, thus transforming these rigid patterns of self-narrative organization. For example, in psychotherapy, a person could begin thinking differently than before, exploring new ways of behaving and relating and gradually feeling differently. All of these occurrences, independent of the form in which they occurred (emotions, behaviors, thoughts), would be considered to be innovative moments (IMs). A systematic tool, the Innovative Moments Coding System (IMCS; Gonçalves, Ribeiro, Mendes, Matos, \& Santos, 2011), was developed to track IMs throughout the treatment. The IMCS allows the identification of five different types of IMs throughout the psychotherapy sessions (Gonçalves, Ribeiro, Mendes, Matos, \& Santos, 2011):

Action IMs - Specific actions that challenge a problematic self-narrative.

Reflection IMs - Feelings or thoughts that reflect new perspectives on the problematic self-narrative and its implications for the client's life. This type of IM can appear in two different forms: type I and type II. Type I reflection IMs can emerge as a new form of understanding the problematic self-narrative and its implications in the client's life or as thoughts that are incongruent with the dominant problematic self-narrative. Type II reflection IMs are centered on the processes of change.

Protest IMs - Actions (such as action IMs) or thoughts (such as reflection IMs) that contain a confrontation against the problematic self-narrative and its assumptions. As in this previous IMs, protest IMs can occur in two forms. Type I protest IMs contain a position of critique against the problematic self-narrative, while type II IMs represent the emergence of new positions.

Reconceptualization IMs - A meta-reflective process that is revealed by an understanding of what has been changing and the processes by which these changes have been occurring. This IM is the most complex type and involves three positions: the self in the past (a problematic facet), the self in the present (a more adjusted facet), and a meta-position from which the change is described.

Performing change IMs - Involve the development of change through new plans, aims or activities.

Table 1 contains descriptions and examples of these IMs.

The IMCS has proved to be a reliable and systematic method of studying the process of change in brief psychotherapy. Studies developed with the IMCS showed good reliability for this coding system across therapeutic models and diagnoses. The average percentage of agreement ranged from $84 \%$ to $94 \%$ for the presence or absence of IMs in transcripts, and the average Cohen's Kappa ranged from 0.80 to 0.97 for the types of IMs that were identified by the coders (Gonçalves, Ribeiro, Mendes, Matos, \& Santos, 2011). The findings of these studies also support the criteria, and convergent and divergent validities of the IMCS (Gonçalves, Ribeiro, Mendes, Matos, \& Santos, 2011). For example, the empirical data from these studies suggest that there is a significantly higher elaboration of IMs in good than in poor outcome cases (Gonçalves, Mendes, Ribeiro, Angus, \& Greenberg, 2010; Matos, Santos, Gonçalves, \& Martins, 2009; Mendes et al., 2011). Furthermore, a pattern of IM changes systematically emerged in these studies, in which reconceptualization clearly discriminates good from poor outcome cases.

From these studies, a heuristic model of change in brief psychotherapy was proposed (Gonçalves et al., 2009). According to this model (see Fig. 1), reflection, action and protest IMs are usually more frequent at the beginning of the therapy. There is no significant difference between good and poor outcome cases at this stage of psychotherapy. These IMs represent the first forms of innovation, which set the ground for further changes to emerge. Thus, in the middle of the therapeutic process, reconceptualization emerges and develops until the end. After the emergence of reconceptualization, performing change is developed. In poor outcome cases, reconceptualization and performing change are rare or absent. This model suggests that it is the emergence of reconceptualization that allows change to be consolidated, because the meta-position allows the diversity of innovations to be organized into a coherent narrative (see Gonçalves \& Ribeiro, 2012; for a detailed analysis of the functions of 
Table 1

Examples of Innovative Moments Vis-à-Vis a Helping Others Dominant Self-Narrative underlying career decision-making problem.

From Gonçalves et al., 2010. Adapted with permission.

\begin{tabular}{|c|c|}
\hline IM type/content & Example \\
\hline \multicolumn{2}{|l|}{ Action } \\
\hline New coping behaviors facing anticipated or existent obstacles & \multirow{5}{*}{$\begin{array}{l}\text { C: This weekend I was able to talk to my husband about the possibility } \\
\text { of leaving my job. }\end{array}$} \\
\hline Effective resolution of unsolved problem(s) & \\
\hline Active exploration of solutions & \\
\hline Restoring autonomy and self-control & \\
\hline Searching for information about the problem(s) & \\
\hline \multicolumn{2}{|l|}{ Reflection: creating distance from the problem(s) } \\
\hline Comprehension reconsidering causes of problem(s) and/or awareness of effects & \multirow{4}{*}{$\begin{array}{l}\text { C: I realized that changing my job wouldn't necessarily leave my } \\
\text { family in a helpless situation. }\end{array}$} \\
\hline New problem(s) formulations & \\
\hline Adaptive self-instructions and thoughts & \\
\hline $\begin{array}{l}\text { Intention to fight problem(s)' demands, references of self-worth, } \\
\text { and/or feelings of well-being }\end{array}$ & \\
\hline \multicolumn{2}{|l|}{ Reflection: centered on the change } \\
\hline Therapeutic process: reflecting about the therapeutic process & \multirow{3}{*}{$\begin{array}{l}\text { C: Yes, these sessions have helped me to see my indecision otherwise. } \\
\text { That makes me feel good, makes me believe that I will be able to solve } \\
\text { the problem. }\end{array}$} \\
\hline $\begin{array}{l}\text { Change process: considering the process and strategies implemented } \\
\text { to overcome the problem }(\mathrm{s}) \text {; references of self-worth and/or feelings of } \\
\text { well-being (as consequences of change) }\end{array}$ & \\
\hline $\begin{array}{l}\text { New positions: references to new/emergent identity versions in face of } \\
\text { the problem(s) }\end{array}$ & \\
\hline \multicolumn{2}{|l|}{ Protest: criticizing the problem(s) } \\
\hline Repositioning oneself toward the problem(s) & $\begin{array}{l}\text { C: I've enough of worrying about the others. What about my life, } \\
\text { my plans, where do they fit? }\end{array}$ \\
\hline \multicolumn{2}{|l|}{ Protest: emergence of new positions } \\
\hline Positions of assertiveness and empowerment & $\begin{array}{l}\text { C: Now it's time to fight for myself, of choosing what I feel is the } \\
\text { best for me. I also want to be happy, feel fulfilled, just be me. }\end{array}$ \\
\hline \multicolumn{2}{|l|}{ Reconceptualization } \\
\hline $\begin{array}{l}\text { Always involve two dimensions: ( } 1 \text { ) description of the shift between two } \\
\text { positions (past and present) and ( } 2 \text { ) the process underlying this transformation }\end{array}$ & $\begin{array}{l}\text { C: Not knowing which direction to take, or which decisions and } \\
\text { choices to make to find myself... It made me feel confused, without } \\
\text { peace. Now it's different. To know where we are, what we want } \\
\text { and the career we want to embrace gives us peace and tranquility. }\end{array}$ \\
\hline \multicolumn{2}{|l|}{ Performing change } \\
\hline Generalization into the future and other life dimensions of good outcomes & CC: The implementation of the new career plans is changing your \\
\hline Problematic experience as a resource to new situations & way of living? \\
\hline Investment in new projects as a result of the process of change & C: Yes, yes. I am starting to see that I can't forget about myself, \\
\hline Investment in new relationships as a result of the process of change & not only at work but also in other dimensions of my own life. Before \\
\hline Performance of change: new skills & I just did tried to answer to everybody's needs but now I am making \\
\hline Reemergence of neglected or forgotten self-versions & time to do things that I really enjoy, that actually make me feel alive. \\
\hline
\end{tabular}

reconceptualization IMs). Moreover, the model also suggests that simpler forms of innovation (action, reflection I and protest I) occur before more developed IMs (reflection II, protest II, reconceptualization and performing change IMs).

\subsection{Return to Problem Coding System (RPCS): Tracking ambivalence in psychotherapy}

The empirical research in psychotherapy with the innovative moments model allowed researchers to identify moments in which an IM emerges, but it is immediately attenuated in its potential for change by a return to the problematic self-narrative.

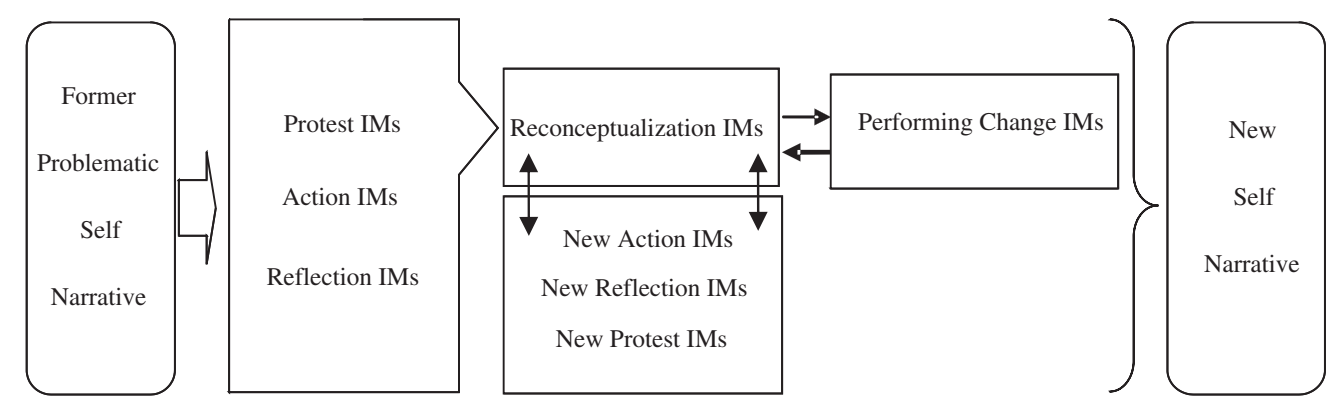

Therapy evolution

Fig. 1. A heuristic model of change on the perspective of Innovative Moments. Adapted from Gonçalves et al., 2009, with the permission from the authors. 
Consider the following example of a client who has a problematic self-narrative that is centered on the theme of career indecision and lack of confidence in his or her own skills:

I realized that being a medicine doctor is what I really want to do (IM) but I don't know if I will ever be able to pursue that (RPM).

This statement clearly reflects a way to reduce the sense of discomfort that results from the possibility of changing. This is a process that aims to preserve self-consistency (Gonçalves et al., 2011) and that reflects ambivalence toward changing.

To study ambivalence in psychotherapy, the Return to Problem Coding System (RPCS) was developed (Gonçalves, Ribeiro, Stiles, et al., 2011) (Fig. 2). In this system, ambivalence is conceptualized as moments at which the novelties (IMs) emerge but are immediately attenuated through a quick return to the problematic self-narrative (Gonçalves et al., 2009; Ribeiro \& Gonçalves, 2010). Obviously, this return to the problematic self-narrative is a form of devaluing the potential for change that is contained in the IM (it may occur as a form of devaluing, trivializing or even negating the idea that meaningful change has occurred).

Research conducted with the RPCS (Gonçalves, Ribeiro, Stiles, et al., 2011) suggests that RPMs (1) are more likely to occur in poor outcome cases than in with good outcome cases; and (2) decrease in good outcome cases from the beginning to the end of treatment but not in poor outcome cases.

\section{Purpose of the present study}

The main aim of this research is to explore the use of both the IMCS and the RPCS in a case of CCC, while studying the patterns of innovation production and the presence of ambivalence in the process of change. Thus, the main question is how change occurred, from the perspective of these narrative models, in a successful case of CCC, extending the scope of applicability of the IMCS and the RPCS to career counseling.

\section{Methods}

The present study analyzes the process of change throughout a CCC case. All of the counseling sessions were coded using the IMCS and the RPCS to track, respectively, the IMs and RPMs.

\subsection{Participants}

Michael was one of the clients who was included in a training DVD that focused on career counseling for three sessions (Savickas, 2009). He was a Caucasian computer science college student who was finishing a major in informatics. At the time of the DVD recording, he lived with his parents. In the first session, he defined his career indecision as "I don't know what direction I want to go. I can't decide if I want to be a race car driver, I want to be an astronaut. I mean I just...I have so much uncertainty". All three counseling sessions were transcribed for intensive analysis with the IMCS and RPCS.

\subsection{Counselor}

The counselor developed the CCC framework and is considered to be an expert on it. This model resulted from 20 years of articulation between theory, research, and practice. For that reason, this DVD is used as a master example of CCC.

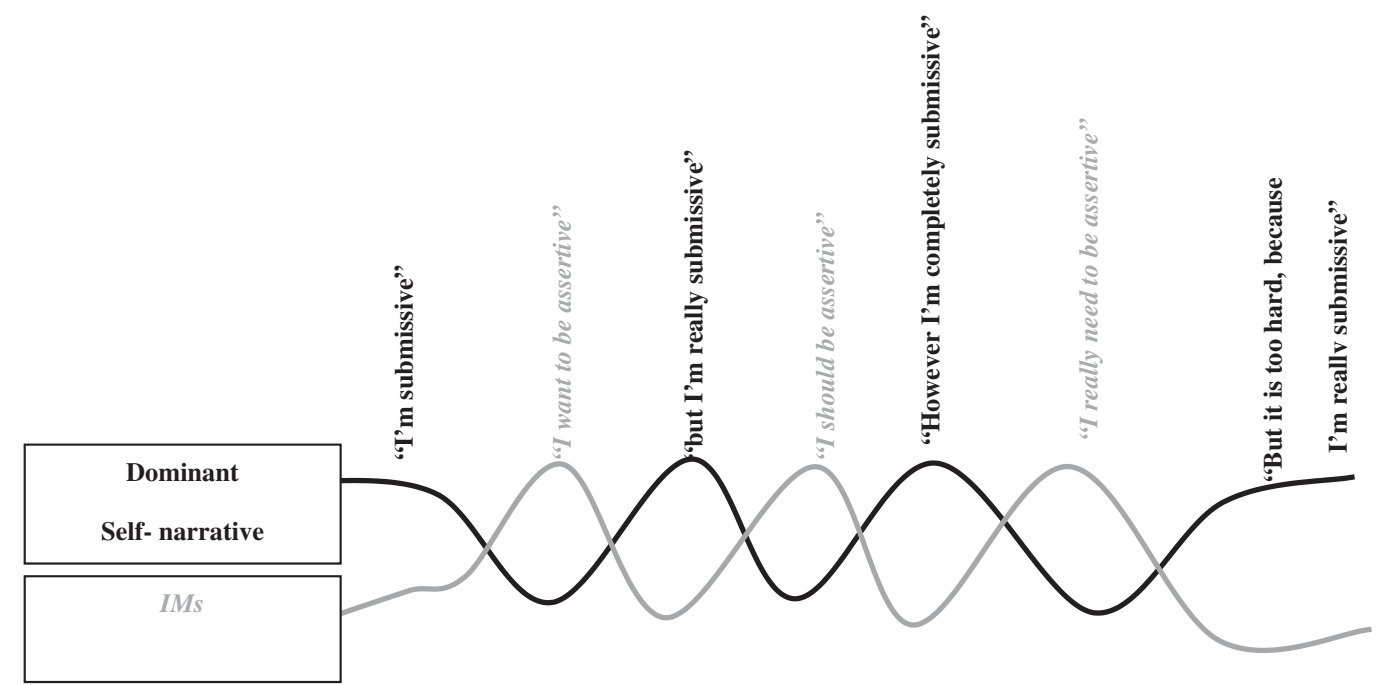

Fig. 2. Ambivalence along the therapeutic process on the perspective of RPMs. From Gonçalves, Ribeiro, Stiles, et al. (2011), with the permission from the authors. 


\subsection{Researchers}

The primary researcher (first author) and coder of the case is a researcher in the field of vocational psychology. He had extensive training and 20 years of experience as a career counselor and was thoroughly trained in the IMCS and the RPCS. The second researcher (second author) has a PhD in clinical psychology and is a member of a team of researchers that studies the therapeutic change processes with the innovative moments model. This single case study was $100 \%$ coded by each of these researchers. The third researcher (third author) is a professor of clinical psychology. Being one of the authors of the IMCS and the RPCS and having experience in IM and RPM coding, he worked as a supervisor and third judge throughout the coding process.

\subsection{Measures}

IMCS (Gonçalves, Ribeiro, Mendes, Matos, \& Santos, 2011). Michael's case was coded using the IMCS to study his process of change during the career counseling. As stated previously, this system discriminates five different types of IMs: action, reflection, protest, reconceptualization and performing change. In the Results section, we will provide examples of the different IMs of the present case.

RPCS (Gonçalves, Ribeiro, Stiles, et al., 2011). This system allows the researchers to track moments in the client's discourse when, after the elaboration of an IM, the client immediately returns to the problematic self-narrative. The RPMs are coded only if they emerge in the same speaking turn of the IM (or in the first speaking turn after the therapists' intervention that immediately follows the IM's elaboration). Examples of the RPMs identified in the present case can be found in the Results section.

\subsection{Procedures}

The first step in the analysis was a careful reading of the entire transcript of the sessions and a consensual definition of the problematic self-narrative. This definition is provided in the Results section. The second step was analyzing the transcripts to track moments at which the client challenged the problematic self-narrative. All of these instances, regardless of their expression form (thoughts, feelings or actions), were coded as IMs (e.g., references to self-confidence, positive feelings, assertiveness or the intention to invest in career exploration as a consequence of the process of change). The identification of the IMs involved 3 operations: (1) Decide when an IM is present, (2) where in the transcript the IM starts and where it is finished, and (3) the type of IM (and in the case of being a reflection or protest, which type it was). The third step was the identification of the RPM. Thus, all of the IMs were analyzed again to check whether, after the elaboration of the IM, the client devalued the IM, by asserting again the problematic self-narrative.

Each session was coded independently and in sequential order (i.e., Session 1, Session 2, and Session 3 ) for the presence of each type of IM and the presence of RPMs. Both the client's discourse and the counselor's discourse were coded. However, the counselor's questions were considered only if the client elaborated subsequently an IM. This coding rule is illustrated in the following vignette in which the counselor and client talk about the fear of failing:

Counselor: I mean if there isn't failure they don't need you.

Michael: Right, because you need to be able to try things and find out what happens when you do this, what happens when you do that.

Counselor: Yes.

Michael: And you need to find every circumstance and probably $90 \%$ of that is failure. (Reflection I IM)

The coding process was consensual, and after the delimitation of the upper and bottom limits of each IM, its salience (i.e., the proportion of the text occupied by the IM) was calculated. The salience of each IM can be defined as the total extension of each IM compared to the total extension of the session in which it occurred. It was computed by calculating the extension of each type of IM, divided by the total extension in the transcript of the session. Usually, the IM's salience is the variable that is used, instead of the IMs' frequency, because it is assumed to be a more direct indicator of narrative elaboration (Gonçalves, Ribeiro, Mendes, Matos, \& Santos, 2011). Salience was computed for separately for the sessions and globally for the entire counseling process (the overall measure of salience).

For the RPMs, the coding process was consensual, and after its identification, two different variables were computed for each session: the overall rate of the RPMs and the RPMs according to each type of IM.

In summary, data analysis took place in a three-step process: (1) identification of the IMs across the transcripts, (2) classification of the IMs according to type, and (3) identification of the RPMs. The whole process was conducted consensually, through the joint codification of the first and second authors with the close supervision of the expert judge (third author). Consensual coding appeared to be the best suitable methodology when considering the exploratory nature of this study.

\subsection{Training and reliability}

Before the study, the coders were trained in the IMCS and the RPM. Training on both systems involved (1) coding of the IMs and RPMs in two different training workbooks; and (2) identification and classification of IMs and RPMs in several psychotherapy sessions. 
For both trainings, Cohen's kappa was calculated at the end of each training phase, with the training considered to be complete only when researchers reached a Cohen's kappa of at least .75. Throughout the training, there were regular meetings with an expert researcher (third author) to discuss doubts and to provide supervision feedback.

\section{Results}

\subsection{Identification of the problematic self-narrative}

As stated above, Michael complained of vocational indecision. However, throughout the first session, it became apparent that underneath his vocational indecision laid a self-narrative that was centered on the theme of sadness regarding the school-to-work transition impasse. The following reply to a question posed by the counselor is illustrative of this theme in his self-narrative.

Counselor: And so, does the sadness you experience, is this getting worse because of the transitions?

Michael: Yes. Like I think I just kind of like, you know, ignored it. And I ignored it because I was so busy with school and like sports .... Just, yes. I could just, you know, ignore it. And then all of a sudden I have to like make these life-changing decisions and I don't even know who I am really I feel like. Or why am I so sad, like, you know, so....

At the beginning of the second session, the client presents a new formulation of the problem: "I feel like I know what I want to do, but I don't do it" and "I think I am not capable of doing it". During this session, the reasons for these statements become apparent. Michael had a fear of failing (e.g., "But it just terrifies me to think about it, because I'm just afraid that it'll suck") and a fear of being himself (e.g., "What I've been told by my parents and friends. My parents, break out of your shell. Like don't be afraid to be who you are"). Throughout the counseling sessions, the aim was to help Michael solve his career impasse that resulted from the above feelings (fear of being incapable and fear of being himself). Thus, the facets of the problematic self-narrative, toward which IMs were identified, were (1) the vocational indecision, (2) sadness regarding the school-to-work transition, and (3) fear of failing (e.g., not being able to take the right choices or stand up to the challenges).

\subsection{Overall IMs during the counseling process}

The IMs occupied 9.7\% of all of the three sessions (the overall duration). However, the duration of the client's engagement in IMs increased throughout the counseling process: $2.1 \%$ in the first session, $7.5 \%$ in the second session and $16 \%$ in the last session. The lower duration of the IMs in the first session can be explained by the fact that this session is centered mainly on the problem's definition and on the assessment of career themes. During the second and third sessions, the counselor deviated from this assessment to encourage the client to elaborate a narrative that allows him to construct a narrative identity and to project new possibilities of self-construction in the work role (Savickas, 2011).

The IM type with the highest salience was reflection (7.2\%), which was followed by protest (1\%) and action (0.6\%).

\subsection{IMs types during the counseling process}

Fig. 3 presents the salience of the IM types in the three sessions. Action IMs appeared only at the beginning of sessions 1 and 3 , when Michael described his efforts on career exploration. Despite its low duration, these events reveal the positive evolution of

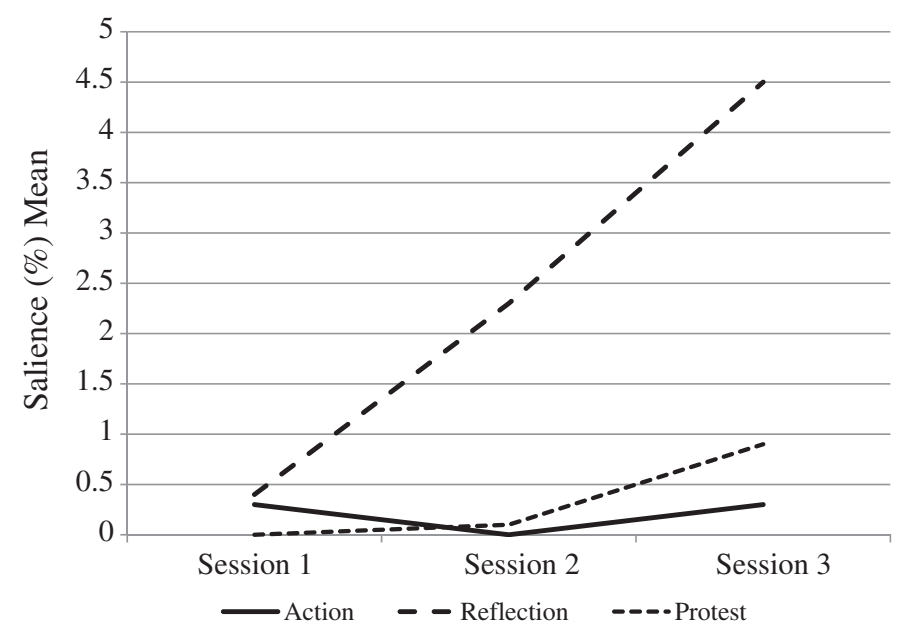

Fig. 3. Evolution of action, reflection and protest innovative moments throughout the career counseling process. 
exploratory behavior, from generalized exploration in the first session to a more focused and specific career exploration in the third session. In the first session, the client said:

Michael: Really, I went to a bunch of career fairs to see what.

Counselor: Good. Good.

Michael: I mean and all those jobs were similar enough where my skills would be applicable and it would be. They could all still be unique in their own rights. So yes, I've done that. Other than that I've gone on career websites (Action IM).

In the third session, the exploratory behavior was much more specific. In the following vignette, the client talks about the sources of information that are required to implement his career plans:

Counselor: How did you find that out?

Michael: Just from talking to a lot of people. Plus, just there's not too many examples I can find of people doing that. Like I said, remember I read that magazine. (Action IM)

Reflection IMs were the dominant type of narrative innovation in all of the sessions. Michaels' engagement in this type of IM substantially increased from session to session. These IMs appear to allow the client to begin creating distance from the problem, through intentions to fight problem demands (e.g., "I could narrow it down"), adaptive thoughts (e.g., "I'm maybe not the first person to step up. But if I see a lack of direction, then I'll go ahead and just say I'll take it and do the best that I can") and new problem formulations. These are dimensions that are typical of reflection I IMs:

Michael: I have all these ideals and values that I like, and it's a matter of just bringing them and then making sure I incorporate them into my life. (Reflection I IM)

This sort of meaning progresses into an increased degree of elaboration, as revealed by this problem formulation expressed at the beginning of the second session:

Michael: There's a disconnect between the motivation to do it. I don't know.

Counselor: Is that how you feel about it? A disconnect sometimes?

Michael: Yes. I feel like I know what I want to do, but I don't do it. (Reflection I IM)

The problem formulation in the vignette above occurred at the beginning of the second session. It allowed the emergence of reflection II IMs, an IM that is centered on change. This type involved contents that are mainly associated with strategies for overcoming the problem (e.g., "I've kind of realized that I have to do some other job first if I want to go into that industry. Using another job as a stepping stone to get into the game industry."), new/emergent identity versions in the face of the problem (e.g., "Until I can conform to the standard I can't really put like guidelines or materialize that standard. But it's whatever I just feel like I'll never be that standard."), and reflections about the counseling process:

Michael: That's why I'm so easy, you know, more comfortable with you telling you all these things versus if I was to tell my parents or tell my friends (...)

Counselor: Because I'm your ally. I'm on your side.

Michael: Yes. You're on my side. (Reflection II IM)

Protest IMs increased significantly from the second to the third session. In the second session, this type of IMs expressed positions of critique against a problematic facet of oneself (e.g., "I'm not an accountant. I'm not an investment banker, I'm not an engineer, right?") or in relation to the problem (protest IMs, type I):

Michael: Right. I'm getting tired of that.

Counselor: And you're getting tired with it, and it's not an intriguing game; it's time for a new game.

Michael: Because I can win that every time. I can keep doing the same thing and I keep getting the same reward, which isn't really a reward in its clear sense.

Counselor: Yes. You've mastered this game. You're at level 60 hardcore on that game.

Michael: That game sucks. Time to move on to the next game. (Protest I IM)

In the third session, protest IMs increased their salience and diversity. For the first time, protest II emerged, revealing Michael's new positions, such as facets of assertiveness and empowerment (e.g., "I'm in charge of my own actions") or the repositioning of himself toward the problem (e.g., "Why would I bother? That's my life").

\subsection{Occurrence of RMPs}

To deepen the study of the change process in CCC, the emergence of RPMs in each session was computed. In the first session, there were no RPMs; in the second session, its occurrence was $25 \%$, and in the third session, this percentage dropped to $12 \%$. These 
results suggest an inverted $U$ evolution of RPM in the counseling process. The ambivalence increased from the first to the second session and then decreased from the second to the third session. All of the RPMs occur following Reflection IMs. An RPM is illustrated in the following vignette:

Counselor: And you can be, you know, intelligent.

Michael: Intelligent [IM] and not know how to talk to anyone [RPM]

\subsection{Follow up}

Follow-up information, obtained four weeks later (by email), revealed that there was some implementation of the new intentions (to take responsibility, to take small steps). Michael did get a job within three weeks after the last session, and he was selected out of 20 applicants to be involved with an entry-level gaming type of job. For that job, he moved away from home to a new city (Savickas, 2009).

\section{Discussion}

The intensive analysis of Michael's case, through the use of IMCS, highlights some dimensions of the process of change during CCC: what changes, and how it changes. The results suggest that the narrative elaboration progresses from the first to the third session. During the first session, action IMs emerged sporadically, while reflection IMs were more expressive. During the second and third sessions, the exploration of the client's story, assessed through the Career Construction Interview, introduced novelty into the problematic self-narrative, as shown by the growing duration and diversity of reflection and protest IMs. This level of change across three sessions is consistent with the IMs' model of psychotherapeutic change. This model assumes that repeated cycles of action, reflection and protest are the first forms of narrative elaboration in psychotherapy (Gonçalves et al., 2009). Moreover, reflection and protest IMs are expected to evolve from type I to type II. In fact, the results found here also support this pattern; in other words, the transformation of reflection IMs from creating distance from the problem (e.g., new problem understanding) to reflection IMs centered on change (e.g., emergence of new identity versions). In a similar pattern, the first protest IMs expressed positions of critique in relation to the problem and the other people who support it (type I), which evolved to protest IMs that are related to positions of assertiveness, empowerment and repositioning oneself toward the problem (type II). These findings are consistent with what was found in good outcome cases in psychotherapy, with the evolution from reflection and protest type I to type II (Mendes et al., 2011).

The results from the present study suggest that the three sessions have allowed for a new understanding of the problem and its consequences, in different dimensions of the client's life. Furthermore, Michael appears to have been able to clarify the central themes in his life and to construct new meanings that are focused on change. The discourse of the client evolved from doubts about what to do ("I feel like I know what I want to do, but I don't do it") to a strong intention to make changes in his life (e.g., "I guess you helped me kind of realize that I can do it... I want it. I really want to do it"). At the end of the third session, his words are revealing "I'm sick and tired of being this way." This evolution allowed the motivational grounds to implement new intentions that occurred later on in practice, as revealed in the follow-up information.

However, in contrast to the results found in psychotherapy with the IMCS, the changes did not lead to the emergence of reconceptualization and performing change IMs. As described above, the initial cycle of IMs, with action, reflection and protest IMs, tends to progress to a higher level of narrative elaboration, in which the client narrates what has changed and how it has changed - i.e., reconceptualization IMs. This capacity to see him or herself changing allows for a consolidation of narrative transformation, which sustains the expansion of the change process into the future (Ribeiro \& Gonçalves, 2010), leading the way to performing change IMs.

Despite this being the first study that applies the IMCS to change in career counseling, we suggest two explanatory hypotheses on the level of the narrative elaboration that were achieved. The first hypothesis is that these IMs are not necessary for change to occur during career counseling. In this type of process, and as opposed to what happens in psychotherapy, action, reflection and protest IMs could work as the main forms of narrative innovation. In other words, these IMs could be, in a sense, the bricks from which career counseling constructs change.

Of course, another explanation is that for reconceptualization IMs to emerge, more time is necessary, given that in psychotherapy these IMs usually emerge in the middle of the treatment, after the 6th session. The good outcomes reported in this case at the follow-up lead us to speculate that the client could be able to elaborate this type of IM at that time, thus allowing him to support his emerging identity and expand it into the future.

In another case study on CCC, this pattern also occurred (Cardoso, 2012). During the counseling process, no reconceptualization emerged, but at a follow-up session (ten months later), the client explored her experience of change, elaborating reconceptualization IMs and even performing change IMs. Moreover, the client also mentioned that the gains in career counseling were not restricted to the work role but were also reflected in her capacity to manage ambivalence at critical points of her life/career. This result is in accordance with the second hypothesis and, of course, deserves further study.

The results also suggest that change is not a linear process and that there is frequently some ambivalence. The RPM analysis was illustrative on this matter, which suggests that, despite the good outcome, Michael revealed some ambivalence throughout the sessions, mainly in the middle session, which is the working phase of the process. This arrangement could be justified by the CCC structure and by the specificity of the client's problematic self-narrative. After the first session in which the CCI was applied, 
Michael was encouraged to rewrite his life portrait by means of a reflection of the central concerns in his life and the possible solutions within the different career roles (Savickas, 2011). This work was conducted with a self-narrative in which the fear of failing was central, which could explain why ambivalence occurred more frequently when IMs emerged that could be characterized by new problem formulations, adaptive thoughts, references of self-worth and intentions to fight the problematic demands.

Future research should study longer CCC interventions that support the implementation of career plans, analyzing whether this approach facilitates the emergence of reconceptualization and performing change IMs. Moreover, these studies could clarify the possibility of using CCC in cases in which a problematic self-narrative underlies career decision-making difficulties. Additionally, the use of IMCS in the study of the change process of clients attending other models of career counseling could provide us with increased information into how career counseling practices might be adapted for clients' needs. At the bottom end, this type of information could allow for an integrative view of change in career counseling.

\subsection{Limitations}

The main limitation of this research is the assessment of the outcome. In fact, this step was conducted through a follow-up session, four weeks after the end of the process, through email. Future studies should consider more formal assessment procedures. Furthermore, this study is exploratory and does not aim to generalize other models or participants. This study was only a first step in the direction of the research on CCC process. Other case studies and research with broader samples are needed.

\subsection{Implications for practice}

Moving from the first intensive case analysis of a CCC process to elaborate practice guidelines is certainly a risky action. Nevertheless, we additionally build upon the extensive research that is centered on the innovative moments in psychotherapy and on the career counseling processes in order to make some very tentative suggestions. The first suggestion includes extending support to the implementation of career plans in order to assure that ambivalence processes do not undermine the evolution of change. This proposal is grounded on research that is focused on IMs in psychotherapy, especially on the evidence that the oscillatory movement between the IMs and the problematic self-narrative in the initial and middle phases of therapy could continue during the entire treatment, making it difficult for significant change to emerge.

The absence of reconceptualization in this case could be a sign that more prolonged interventions should be supported. Of course, more research is needed to make this aspect clear. Additionally, in favor of a more prolonged intervention is the fact that career plan implementations can be a very demanding task (Germeijs \& Verschueren, 2007; Jome \& Phillips, 2005; Phillips, Blustein, Jobin-Davis, \& White, 2002). Furthermore, the client's problem could be related to having difficulty in moving toward action, as was mentioned by Michael: "I feel like I know what I want to do, but I don't do it". In fact, Savickas (2011) has argued that, for some clients, the career barriers that are associated with maladaptive thoughts and emotions make acting more challenging. Perhaps increasing the number of sessions could allow the clients to achieve reconceptualization and performing change IMs, facilitating more stable changes and facing the difficult challenges that can emerge throughout the implementation of career plans. Practicing this suggestion is also supported by research on career counseling, which proposes that, in these cases, the intervention should be longer (Heppner \& Hendricks, 1995) and should be conducted in the more supportive style of career counseling (Anderson \& Niles, 2000; Rochlen, Milburn, \& Hill, 2004).

The final implication for practice comes from the IM model of change (Gonçalves et al., 2009), by suggesting that IMs could work as important markers for counselors, to amplify the clients' narrative transformation after considering their current level of narrative change. As an example, counselors could help the client to engage in a more deep reflection of the client's life portrait after a low level of change has occurred (e.g., action, reflection I and protest I). In this sense, questions that are focused on what is similar and different in the client's life and in his or her representation of the processes that are involved in the transformation could facilitate the emergence of more developed IMs, such as reflection and protest type II or even reconceptualization IMs. Additionally, and with the goal of achieving continuity in the client's narrative transformation, the counselor could question the client about the impact of change throughout the full range of his or her career and personal roles, thus facilitating the elaboration of performing change IMs.

\section{Acknowledgments}

This article was supported by the Portuguese Foundation for Science and Technology (FCT), by the Grant PTDC/PSI-PCL/ 121525/2010 (Ambivalence and unsuccessful psychotherapy, 2011-2014).

\section{References}

Anderson, W. P., Jr., \& Niles, S. G. (2000). Important events in career counseling. Client and counselor descriptions. Career Development Quarterly, 48, $251-263$. Cardoso, P. (2012). Maladaptive repetition and career construction. Journal of Vocational Behavior, 81, 364-369. http://dx.doi.org/10.1016/j.jvb.2012.09.003. Di Fabio, A., \& Maree, J. G. (2011). Group-based life design counseling in an Italian context. Journal of Vocational Behavior, 80, 100-107. http://dx.doi.org/ 10.1016/j.jvb.2011.06.001.

Dimaggio, G. (2006). Disorganized narratives in clinical practice. Journal of Constructivist Psychology, 19, 103-108. 
Germeijs, V., \& Verschueren, K. (2007). High school students' career decision-making process: Consequences for choice implementation in higher education. Journal of Vocational Behavior, 70, 223-241. http://dx.doi.org/10.1016/j.jvb.2006.10.004.

Gonçalves, M. M., \& Ribeiro, A. P. (2012). Therapeutic change, innovative moments and the reconceptualization of the self: A dialogical account. International Journal of Dialogical Science, 1, 81-98.

Gonçalves, M. M., Matos, M., \& Santos, A. (2009). Narrative therapy and the nature of "innovative moments" in the construction of change. Journal of Constructivist Psychology, 22, 1-23. http://dx.doi.org/10.1080/10720530802500748.

Gonçalves, M. M., Mendes, I., Ribeiro, A., Angus, L., \& Greenberg, L. S. (2010). Innovative Moments and change in emotional focused therapy: The case of Lisa. Journal of Constructivist Psychology, 23, 1-28. http://dx.doi.org/10.1080/10720537. 2010.489758.

Gonçalves, M. M., Ribeiro, A. P., Mendes, I., Matos, M., \& Santos, A. (2011). Tracking novelties in psychotherapy process research: The innovative moments coding system. Psychotherapy Research, 21, 497-509. http://dx.doi.org/10.1080/10503307.2011.560207.

Gonçalves, M. M., Ribeiro, A. P., Stiles, W. B., Conde, T., Matos, M., Martins, C., et al. (2011). The role of mutual in-feeding in maintaining problematic self-narratives: Exploring one path to therapeutic failure. Psychotherapy Research, 21, 27-40. http://dx.doi.org/10.1080/10503307.2010.507789.

Heppner, M. J., \& Hendricks, F. (1995). A process and outcome study examining career indecision and indecisiveness. Journal of Counseling and Development, 73(426), 437.

Heppner, M. J., \& Heppner, P. P. (2002). Identifying process variables in career counseling: A research agenda. Journal of Vocational Behavior, 62, 429-452. http://dx.doi.org/10.1016/S0001-879(02)00053-2.

Hermans, H. J. M., \& Hermans-Jansen, E. (1995). Self-narratives: The construction of meaning in psychotherapy. New York: Guildford.

Jome, L., \& Phillips, S. (2005). Counseling for choice implementation. In S. Brown, \& R. Lent (Eds.), Career development and counseling: Putting theory and research to work (pp. 466-481). London: John Wiley and Sons.

Matos, M., Santos, A., Gonçalves, M. M., \& Martins, C. (2009). Innovative moments and change in narrative therapy. Psychotherapy Research, 19, 68-80. http://dx.doi.org/10.1080/10503300802430657.

McAdams, D. P. (1993). The stories we live by. New York: Guilford Press.

Mendes, I., Ribeiro, A. P., Angus, L., Greenberg, L., Sousa, I., \& Gonçalves, M. M. (2011). Narrative change in emotion-focused psychotherapy: A study on the evolution of reflection and protest innovative moments. Psychotherapy Research, 21, 304-315 (doi: 10.1080.10503307.2011.565489).

Phillips, S. D., Blustein, D. L., Jobin-Davis, K., \& White, S. F. (2002). Preparation for the school-to-work transition: The views of high school students. Journal of Vocational Behavior, 61, 202-216. http://dx.doi.org/10.1006/jvbe.2001.1853.

Refhuss, M. C., Cosio, S., \& Del Corso, J. (2011). Counselors' perspectives on using the Career Style Interview with clients. Career Development Quarterly, 59, $208-218$.

Refhuss, M. C., Del Corso, J., Glavin, K., \& Wykes, S. (2011). Impact of the Career Style Interview on individuals with career concerns. Journal of Career Assessment, 19, 405-419. http://dx.doi.org/10.1177/1069072711409711.

Ribeiro, A. P., \& Gonçalves, M. M. (2010). Innovation and stability within the dialogical self: The centrality of ambivalence. Culture E Psychology, 16, 195-212. http://dx.doi.org/10.1177/1354067X09353211.

Rochlen, A. B., Milburn, L., \& Hill, C. E. (2004). Examining the process and outcome of career counseling for different types of career counseling clients. Journal of Career Development, 30, 263-275.

Sarbin, T. R. (1986). The narrative and the root metaphor for psychology. In T. R. Sarbin (Ed.), Narrative psychology: The storied nature of human conduct (pp. 3-21). New York: Praeger.

Savickas, M. L. (2005). The theory and practice of career construction. In S. D. Brown, \& R. W. Lent (Eds.), Career development and counseling: Putting theory and research to work (pp. 42-70). New York: John Wiley.

Savickas, M. L. (2009). Career counseling over time [DVD] (Psychotherapy in Six Sessions Video Series). Washington, DC: American Psychological Association.

Savickas, M. L. (2011). Career counseling. Washington, DC: American Psychological Association.

Savickas, M. L. (2013). Career construction theory and practice. In R. W. Lent, \& S. D. Brown (Eds.), Career development and counseling: Putting theory and research to work (pp. 147-183) (2nd ed.). Hoboken, New Jersey: John Wiley \& Sons.

Whiston, S., \& Rahardja, D. (2008). Vocational counseling process and outcome. In S. D. Brown, \& R. W. Lent (Eds.), Handbook of counseling psychology (pp. 444-461) (4th ed.). New Jersey, NJ: John Wiley.

White, M., \& Epston, D. (1990). Narrative means to therapeutic ends. New York: W.W. Norton. 